\title{
Experience in training art specialists
}

\author{
L.V. Stepanenko ${ }^{1 *}$, and E.L. Plavskaya ${ }^{2}$ \\ ${ }^{1}$ Novosibirsk State Technical University, Novosibirsk, Russia \\ ${ }^{2}$ Novosibirsk State Technical University, Novosibirsk, Russia
}

\begin{abstract}
In periods of social upheaval, historically turning points in the life of society, an appeal to the world of arts, artistic creativity, revealing a different reality to a person, re-created according to aesthetic canons - and is sometimes the world that a person needs, that system of value guidelines, on the basis of which it is spiritually strengthened or revived. That is why we singled out art education as a direction directly related to the spiritual development of a student, capable of expressing the actual ideas of the time through the immanent language of arts (of all types, directions and stylistic searches, genres). At the present stage, art education (as in the first third of the last century, when it received a structural and substantive design) is characterized by exploration and experimentation, therefore, the historical analogy carried out allows us to see the repetition or fundamental novelty of the processes aimed at preparing the student of the art profile.
\end{abstract}

\section{A problem statement}

We will try to consider the process of training specialists in the field of art education using the example of the West Siberian region. Due to the historical and cultural features of the development of Western Siberia - its historically late (territorial-geographical and administrative-managerial) design - the processes of influence of European Russia on art education took place here later (only by the second third of the 19th century). Therefore, the problem of interaction between the region and European Russia in terms of enhancing the forms of exchange of pedagogical experience in the organization and training of art specialists with an emphasis on regional specifics does not lose its relevance. In this context, we pay special attention to the active participation of both state administrative bodies (central and local government bodies) and the general pedagogical community (cultural figures, representatives of professional and creative unions - artists, musicians, writers, theatrical figures) in the search for forms of their constructive interaction with the aim of actualizing precisely artistic direction in education as fulfilling a special mission of spiritual enrichment. Thus, the relevance of our work is determined by the need to analyze the development of regional art education - the specifics of the content, the conditions for the disclosure of the artistic and creative potential of students, the training of teaching staff,

\footnotetext{
*Corresponding author: prof-ped.gpa@mail.ru
} 
necessary for an in-depth study of this experience and designation of the possibilities of its application in further pedagogical practice and in artistic educational activities of those specialists who were trained in art educational institutions.

\subsection{The objective of the work}

Questions related to the topic of our research - the disclosure of artistic and creative potential and the formation of personal qualities of students in art institutions, the ratio of traditional and innovative approaches to the organization of the educational process - are presented in the scientific literature.

The theoretical and methodological positions of this work were based on works covering modern approaches in scientific and pedagogical research - Sh.A. Amonashvili [1], V.I. Zagvyazinsky [2], L.A. Stepashko [3], L.A. Burovkina [4], etc., necessary in the organization and construction of our research.

The ideas of the spiritual formation of a person presented in the works of domestic and Western European educators and thinkers - J. Dewey [5], P.F Kapterev [6], Ya.A. Komensky [7], R. Berne [8] and others, allowed us to consider art education as one of the organic components of the humanitarian sphere in the context of the spiritual development of a person and society, which influences the formation of a system of moral and ethical imperatives, on the basis of which socio-cultural interaction takes place.

The theories of personal growth-development and motivational activity by L.S. Vygotsky [9-11], T.I. Ivanyuk [12], A.N. Leontiev [13], A. Maslow [14] and others, are the basis for revealing the creative potential of students in the framework of art education. These works helped to diversify the process of personal growth and development of the student: the identification of natural and genetic inclinations and the development of artistic and creative abilities (plastic, figurative-associative, linguistic, figurative-emotional, musical, communicative, etc.), the study of nationally distinctive traditions and works of academic artistic culture, the ability to interpret works of art and actualize their own artistic and creative searches. The reliance on the data of psychological and pedagogical research allowed us to understand the differentiation of the artistic and creative abilities of students, determining the specifics of artistic and creative activities, identifying the degree of motivation of the student's personal growth and development.

Works on the theory and history of art, the typology of artistic culture and its evolution, the actualization of art education by M.S. Kagan [15], V. Hoffman [16], L.N. Kogan [17], Yu.M. Lotman [18], M. Heidegger [19], M.N. Epshtein [20], B. Taylor [21] and others, helped us to structure art education, to understand the conceptual basis of its content related to the inheritance and rethinking of artistic values by subsequent generations. Art education is associated with the purposeful study of the fundamentals of the arts by students (awareness of the generic, specific, genre and social differentiation of arts), with the understanding of the socially significant activities of the artist (painter, sculptor, architect, composer, etc.), with the definition of directions and forms of popularization of works of art, and, of course, with the identification of the artistic and creative potential of the student, tracking his growth and development, entering the artistic and educational life. Issues related to the study of the peculiarities of the functioning of art educational institutions at the regional level, intercultural interaction and partner dialogue, which are reflected in the works of modern researchers - S.I. Kolbysheva [22], E.V. Savelova [23] and others, allowed us to single out art education as an independent direction, which received a holistic structural and content design, having regional specificity and development prospects in terms of expanding the geography of cooperation in this area. 
The issues of organizing the educational process, taking into account the modern requirements of the transition from the traditional model to the competence-based model, which were covered in the works of V.S. Senashenko, A.A. Makarova [24], E.O. Pakhomchikova [25] and others, helped to study the modern pedagogical experience and project it onto the training system for art specialists.

Our study of scientific literature has shown that art education arouses research interest in terms of: its evolutionary history; the formation of conceptual foundations of the content; the specifics of teaching and upbringing, taking into account the continuity and innovativeness of the activities of educators-innovators from European Russia, the region and other countries; a practice-oriented focus educational process. But we would like to dwell separately on identifying the specifics of art education in the context of socio-cultural modernization in order to actualize the artistic, educational and pedagogical activities of art specialists.

In our work, we proceeded from the assumption that the pedagogical experience of the development of art education (at the regional level) can be effectively used in modern conditions, if a historical and retrospective review is presented, an analysis of the theoretical and practical components of the process of teaching and upbringing in the system of art education and the correlation of traditional (not losing their relevance) and innovative approaches in the organization of the educational process in terms of training art specialists has been carried out.

Therefore, we relied on the principles of scientific objectivity, reliability, which predetermined the desire for an unbiased consideration of the historical and pedagogical process, made it possible to assess the true contribution of teachers, representatives of the general public in the training of art specialists.

\section{Results of the research}

The development of regional art education (on the example of the West Siberian region) is considered by us in the context of the connection between history and modernity, the actualization of positive organizational and pedagogical experience and the possibilities of its application in modern pedagogical and artistic-educational activities. Regional art education is characterized as a direction that has received an independent consolidation in educational practice, which has the same principles of construction and development for the domestic and European (since Russia's entry into the Bologna process) educational space. Namely: typification (introduction of new types of educational institutions - lyceums, colleges), integration (entry of educational institutions of primary or secondary vocational education as structural units in the higher echelon), level (bachelor's - master's degree). All these principles in different ways highlight the internal logic of the development of art education, which is sealed by the main idea - continuity. Studying the experience of organizing regional art education, we will try to see its application in modern practice and identify promising ways of development.

The main idea in the development of Russian education today is the idea of sociocultural modernization, in which the key positions that determine the quality of education at the present stage are highlighted. The modernization process is aimed at creating mechanisms for the sustainable functioning of the education system on the basis of an updated regulatory framework, structuring, the formation of conceptual foundations of the content and the construction of didactic tools. The concept of sociocultural modernization characterizes the training of professionally competent, socioculturally adapted and socialized people in the modern cultural life. In projection onto the personality 
of the student, the socio-cultural modernization process reveals the main thing - the need to orient the student not only to the process of increasing knowledge, abilities, skills, but also to the development of creative qualities of the individual, building up professional skills, expanding the experience of participation in artistic and creative activities, finding ways and forms of artistic and creative self-realization.

Having studied the historical and pedagogical experience of organizing regional art education, we highlight the main directions of socio-cultural modernization: - renewal of the structure of arts education; - updating the content of art education in terms of the development, testing and implementation of educational programs, the formation of modern approaches to the content of art education, teaching and upbringing methods; strengthening of the practice-oriented orientation of the educational process, the organization of regional, all-Russian and international scientific and practical conferences, seminars and other events in order to improve the process of training art specialists. Let us dwell on their characteristics in more detail.

The processes of structuring regional art education can be seen: in its gradual formation in the general education system over a fairly extended period; in out-of-school education, which was developed at the turn of the 19th - 20th centuries; in vocational education. Having studied the features of its design, we consider it necessary to note that in the second third of the XX century a stable structure was formed, on the basis of which the further systematization of regional art education took place, which allows us to consider it in the aspect of "tradition and its renewal". In the second half of the twentieth century, changes were observed in only one of the components - professional art education, which developed as a multi-level one, enriched with higher echelons and postgraduate education (the Conservatory in Novosibirsk, the Art Institutes in Omsk, Kemerovo, the faculties of arts at the Pedagogical Institutes of Omsk, Tomsk, Tomsk State University).

Perestroika processes in the art education of the West Siberian region also took place in the 1990s. The actual ideas of that time were the orientation towards Western European models in education and integration. They were seen in: renewal of the initial link of professional art education - the emergence of new models of educational institutions lyceums; the transformation of vocational art education in the middle tier - renaming art schools into art colleges; reorganization of the highest level of professional art education the creation of educational institutions of a new - integrated type - the Academy of Arts, including primary, secondary and higher professional education.

Speaking about the development of primary art education - the activities of schools (lyceums) of arts, music, art, - we pay special attention to the fact that it reflects the idea of the continuity of historical experience and modern practice of organizing and building work. Having deep roots and strong traditions (this link of primary vocational education), it is designed to create the necessary conditions for identifying natural genetic inclinations, developing artistic and creative abilities, and carefully leading along the path of creative growth to continue education at a different level.

In connection with the creation in the middle and higher levels of professional art education of educational institutions of a new - integrated type (as the result of the implementation of the Bologna process in the early 2000s), we note especially close attention to the quality of training of qualified specialists using modern information and communication technologies. Fundamentally new directly in the field of higher education, including art, was the transition to a two-tier system (bachelor - master), which became the basis for creating a new structure of qualifications and specialties. The educational task of the first level is to form the foundations of professional culture and basic activity competencies (communication skills, information search and analysis skills, self-education, teamwork skills, etc.). Education in the master's program is aimed at training specialists 
capable of organizing new areas of activity based on the use of active forms and modern teaching technologies in the educational process - all this makes it possible to implement the concept of practice-oriented education in the master's program, including the training of a modern corps of researchers.

However, in our opinion, it is noteworthy that in the historical practice of professional art education the system "school - college - university" has been consolidated and the exclusion of one of the links can lead to the loss of such a unique historical and pedagogical experience of building and development, which is recognized as a national cultural heritage. Our efforts are aimed at confirming once again within the framework of this study that the system of art education has developed and functioned steadily, which today needs to be preserved and identified for further use of the accumulated experience. Art education is an internally holistic system in which each of the elements has its own typed solution and is the basis for the development of students' artistic and creative abilities, or the formation of the foundations of professional culture and further improvement of the student's professional skills.

Art education in the context of socio-cultural modernization is also undergoes substantial changes. Excessive ideologization of the educational process has gone from modern practice as a special sign of the Soviet era. The same can be said about the ideological pressure in the "broadcast" of works of art, about a selective approach to works of art, towards their creators, focusing on "social orders" reflecting key ideas in education (the formation of the type of personality that society needs in a particular period ). Art education today opens up a wide field of artistic and creative activity for students, presenting the widest panorama of the arts, the entire palette of artistic styles, stylistic searches of creators, possible synthesis (mixed) options of different arts - full immersion of the student in the multifaceted world of artistic creativity. The focus of art education on expanding the information field of the content of art culture is seen as relevant in modern practice. The idea of polyart education lies in the fact that art education today is becoming a field of active interaction between different types of arts, different directions of artistic and creative activity, the development and use of modern technical means.

The specificity of teaching and upbringing students in the art sphere is associated with the acquisition of knowledge about the basics of the arts (generic, species, genre differentiation, history and theory of arts), the development of skills and abilities in the language of art (the formation of the performing apparatus among musicians; the formation of the motor apparatus and the development of artistic and plastic abilities among those involved in choreography; the formation of figurative-associative thinking among artists, architects, sculptors; the development of the abilities of figurative transformation among actors), the acquisition of experience of independent creative activity in one form of art or another, the formation of a system of values based on the development of artistic tastes, assessments, judgments, needs.

From here, a didactic toolkit is built on the basis of the correlation of goals and objectives, content, methods and organizational forms. So, the goal of art education is to educate a person who knows, who is able to think creatively, to apply the knowledge gained in life. Only such a person is distinguished by the activity of perception and action. The goal-setting system that responds to the challenges of modern society includes: attitude to the student's personality as a subject of education, the development of a creatively oriented personality capable of searching, heuristic, novelty, non-standard solutions, and original manifestation. It is thanks to this - careful - approach to the personality of the student that the necessary and demanded qualities are formed: socio-cultural adaptability, socialization, sociability, tolerance. 
In connection with the expanded field of goal-setting, the following tasks are formulated: preservation of the principle of conformity to nature (the original nature of the child) and careful development of his artistic and creative abilities (plastic, figurativeassociative, figurative-emotional, verbal, musical, communicative); the development of the creative nature of the student's personality and the creation of a creative environment psychological freedom for the realization of creative potential: non-standard ideas, thoughts, actions, their acceptance and stimulation of the ability of independent artistic and creative search; development of higher mental functions (perception, feelings, emotions, memory, thinking, imagination, speech) through the arts of different types and genres; the formation of skills of independent cognitive and practical activities of students through their participation in various forms of artistic and educational activities.

An important part of the didactic toolkit is made up of the methodological principles of artistic teaching and upbringing, preserved and updated by modern pedagogical practice. The methodological basis of the process of artistic teaching is the co-creation of a teacher and a student, which is based on the principles of differentiation and individualization of teaching.

The methodology of artistic training and education is very specific. She immerses a person in the world of art. This is a special world in which reality is reflected, but not photographed, but rethought through the prism of individualized-artistic perception. In this regard, the very process of re-creating reality according to the canons of beauty is creative, in which novelty, non-standard vision, unconventional solutions in human interpretation of the picture of the world through the language of art are important. In itself, the process of studying works of art (painting, sculpture, music, etc.) is a creative activity - innovative, associated with heuristic discoveries. Two parties are equally involved in it - both the teacher and the student.

In this regard, the mentor must have professional erudition and a very broad general cultural thesaurus (knowledge base). The specificity of art education and upbringing lies in the fact that the teacher himself must conduct an active creative activity - an exhibition for an artist, a concert for a musician, etc., in order to be a vivid example for students himself. In addition, his task is related to the disclosure of the student's creative abilities, finding for him an individual teaching methodology. The teacher must not only convey the technical arsenal - directly techniques, skills in mastering the language of art, but develop in the student the ability to analyze the psychological, figurative-emotional structure of a work of art. The awakening in the student of the ability to reveal the gamut of feelings, which the artist sought to convey, to introspection is one of the important components of the organization of the learning process. In addition, the teacher's task is associated with the development of the student's thinking abilities - the ability to interpret the artist's intention (to build storylines according to reference signals, to formulate a storyline).

Within the framework of art education, it was not by chance that a certain form of study was chosen - individual training. One of the main pedagogical tasks is associated with the disclosure of individual abilities and unique personal qualities in the student. The arrival of a person in the world of art is either intuitive or conscious. And here an important role is played by the environment - the socio-cultural environment (the immediate environment the family as the first social institution, which can facilitate the discovery of certain abilities in the child, develop him in this direction). In the very process of teaching and upbringing, the student is faced with a set of tasks, which include: mastering technical skills, techniques; development of figurative-emotional and associative thinking. However, one of the important ideas is associated with the enrichment of the imagination, which comes with the expanding experience of acquiring professional knowledge and life lessons. 
We especially note the flexibility of the mentor's position, who needs to find an organic form of interaction in which the student could maximize his abilities with greater success: based on the idea of humanization - teaching and upbringing from a position of nonviolence, faith in the potential abilities and creativity of the student's nature. It is the mentor who must demonstrate the skill of communication - co-creation, companionship, tolerance (the student's right to make a mistake, the right to make his own choice), the ability to convince by personal example, the priority of positive stimulation.

Consequently, the principles of individualization and differentiation of education and upbringing presuppose: the development of individual programs in order to determine the orientation of the individual to the development of creative abilities in specific types of art; taking into account personality traits in the educational process; forecasting the possibilities of personal growth and development, disclosing the motivational and volitional qualities of the student; the formation of cognitive-axiological representations (logical skills, heuristic skills, value orientations).

In modern reality, the idea of forming the information capital of the student's personality has been updated. In projection onto the system of art education, this can be seen in the disclosure of various artistic and creative abilities of a person, his synthetic nature, further development in the direction of mastering various types of arts and selfrealization through art.

The specificity of art education lies in the organization of art and educational activities of both the teaching staff and students. Therefore, we note very important aspects that have received historical consolidation and that do not lose their relevance in modern practice: the successive practical activities of teachers from European Russia and the region in terms of the emergence of new directions, forms of artistic and educational activities that have become traditional in European Russia and innovative for the region; close interaction of teachers and students in the organization of artistic and educational activities.

The socio-cultural design of regional art education was aimed at identifying the relevance of this direction as solving the most important tasks - meeting the needs for disclosing and developing the creative abilities of the younger generation in the field of arts, the formation of the younger generation's worldview by means of art of all types and genres, and most importantly, the formation of the foundations spirituality due to the fact that artistic training, artistic education is associated with broadening one's horizons, acquaintance and study of folklore heritage (oral folk art), monuments of artistic culture (creativity of artists, modern trends in artistic culture, reflecting the spiritual landmarks of modern times).

The leading ideas for training specialists, based on modern requirements, are their awareness of the socio-cultural orientation of the process of art education, the connection with educational activities of both teachers and students. The involvement of the student in active educational activities was an important aspect in terms of strengthening professional skills, dynamizing the learning process, its effectiveness, students' awareness, even at a young age, of a certain role in social and cultural life. Thanks to this, he is able to choose adequate forms of self-realization in the future - engaging in pedagogical, organizational or educational activities. Therefore, the arrival of a person in the world of art and his personal development must be motivated by the person himself. The world of art for him should be organic: through it he learns the world around him, in it he finds his own harmony and can most fully express his individuality.

The practical and activity side of art education is based on the close procedural interaction of a teacher and a student, and is aimed at mastering new teaching methods, introducing organizational forms, involvement in cultural life in order to identify professional adaptation, socio-cultural activity, creative attitude to the chosen activity - 
participation in contests, olympiads organized within the framework of intercultural interaction (Region - European Russia - West - East). So, very relevant for the first half of the XX century directions of organizing the artistic and educational activities of teachers and students at the Gorno-Altai art school, Omsk Art and Industrial College named after M.A. Vrubel [26] were: advertising and exhibition - the organization of exhibitions of works by artists in different genres (portrait, still life, landscape, historical canvases), sculptural compositions; decorative (for the decoration of the premises of the panel, the creation of sculptural compositions of the facades of buildings); architectural and landscape (creation of sketches for the design of natural, urban landscapes). Describing these areas, we note that in modern practice they are seen as very much in demand due to the active development of urban infrastructure.

Teachers and students of music schools and music colleges from Tomsk, Omsk, and later Novosibirsk [26] over the more than a century history of these institutions have been active in concert, performing at different venues: in sponsored collective farms, garrison units, houses of culture, before movie shows, citywide concerts, on the radio, polling stations. They formed musical teams that performed at various concert venues in the region. In our opinion, the idea of creating concert brigades that performed enlightenal, educational, agitation and propaganda functions deserves special attention. Concert activities of professional groups and performers have not exhausted themselves in modern conditions.

Teachers and students of the School of Culture and Art from Kemerovo, a choreographic school from Novosibirsk organized performances, performed with choreographic miniatures, scenes from performances. Theatrical schools and institutes of culture in Novosibirsk and Omsk also presented theatrical performances and organized entertaining performances.

It is thanks to this popularization of works of art of different types and genres, through various forms of presentation, directly teachers and artists were active participants in the development of artistic views, tastes, judgments of both the younger generation and the general public. Artistic and educational activity is an important part of the art education process in the sense that both teachers and students of art educational institutions, mastering new directions and forms, go out to a wide audience, thereby forming its artistic tastes and landmarks. All this allows us to speak about the importance, social relevance of the process of popularizing the arts, aimed at expanding the audience, about the importance of such events in terms of its artistic education.

The importance of artistic and educational activities is also associated with the acquaintance of the younger generation of spectators, listeners with art monuments (classical heritage) and works of contemporaries through different directions. In this regard, artistic and educational activities were not only practice-oriented, but also socially in demand due to the fact that they promoted new directions that aroused public interest.

Tracking the further practice of the selected areas made it possible to ascertain their socio-cultural relevance and even actualization at the present stage, noting the main thing activities within these areas are associated with the development of students' personal qualities - social and cultural activity, erudition, adaptability, which are important in terms of human self-orientation. In a highly competitive labor market, in our opinion, is seen as relevant in modern art education the preservation of the historically established principle of organizing the educational process - combining or alternating educational activities with the practical participation of students in the cultural life of the region. This is what is a constituent part of the professional growth and development of the student's personality in the artistic sphere - motivation of behavior, adaptability in the socio-cultural environment, enrichment with new knowledge in terms of expanding the historical and cultural field, 
acquiring new skills (interpretation of works of art) and acquired habits (public presentation of one's own activity, adaptation to public opinion), expanding the field of artistic and creative activity through search and experimentation with forms and genre diversity.

In the course of studying the process of preparing students in the art sphere, we identified the provisions that are promising:

- art education has been developed thanks to the successive educational and enlightenal activities of teachers of European Russia in the region due to the migration of teaching staff from European Russia to the region, the unification of the wide pedagogical community in professional and creative unions, the activation of forms of exchange of pedagogical experience with a gradual expansion of the geography of interaction (demonstration classes methodological seminars, conferences, olympiads, review contests);

- new directions have been developed (architectural and landscape, decorative and design, advertising and exhibition, theatrical production, choreographic, concert and philharmonic, etc.) and forms (olympiads, shows, competitions, Delphic Games; mass media) of artistic and educational activities of teachers and students of art educational institutions and educational institutions.

The theoretical significance of our work lies in the fact that the existing ideas about the artistic education of students are supplemented by the fact that a retrospective analysis of development experience made it possible to present it as a direction that has its own history of origin and development associated with the acquisition of structural and content integrity based on the principles of typification, systematization, integrativity, leveledness, continuity. Consideration of the educational process as practice-oriented made it possible to characterize the types, directions and forms of art and educational activities as innovative for the region and successive in terms of interaction between European Russia and the region, which can contribute to the development of the problem of the importance of training future specialists in the system of regional art education.

The practical focus of the work is to identify positive experience in the development of regional art education, which can be used in the course of building an effective organizational and pedagogical activity aimed at training a specialist at the present stage, namely:

- the continuity of the educational and enlightenal activities of teachers of European Russia in the region due to the migration of teaching staff from European Russia to the region, the unification of the wide pedagogical community in professional creative unions, the activation of forms of exchange of pedagogical experience (demonstration classes, methodological seminars, conferences, olympiads, contests) with the expansion of the geography of pedagogical interaction;

- organization and construction of a pedagogically holistic process of regional art education of students (with the definition of goals and objectives aimed at disclosing the artistic and creative abilities of students; the specifics of content related to obtaining knowledge about the basics of the arts, acquiring the skills of improvisation and interpretation of works of art, developing skills in using materials arts, relying on ethnocultural characteristics (national-regional component) in drawing up curricula in the subjects of art; strengthening individualized and differentiated approaches to students based on the variability of educational programs adapted to the abilities and capabilities of each student; practice-oriented focus due to the increased role of modern media and technologies in the artistic and educational process);

- active interaction of teachers and students, which led to the development of the existing and popular today areas of artistic and educational activities (architectural and landscape, decorative and design, advertising and exhibition, concert and performance, 
theatrical production, etc.), forms of artistic education (Olympiads , shows, contests, Delphic Games); mass media.

Improving the quality of training and retraining of pedagogical personnel, increasing the importance of art education for children and youth in the context of modern socio-economic and cultural development of Russia, promoting the development of professional education in the field of culture and art remains relevant today. Moreover, art education has developed along the path of establishing contacts with public, professional organizations of foreign countries in order to exchange experience on the content and organization of the process of art education - this is an important direction in terms of expanding the geography of intercultural interaction West - Russia - East - region. International activity in the field of training socialists for the sphere of culture and art is very productive, its significance and prospects for development and partnerships are recognized and supported by all participants in both the educational process and artistic and educational activities organized by them in different geographic locations. The following are seen as promising forms of work: the organization of joint educational activities (master classes) between partners, the development of advanced training programs for the teaching staff, the expansion of scientific interaction, the organization of joint projects of artistic and creative activities.

\section{Conclusions}

Thus, the regional art education of students received a structural, meaningful design. Structural renewal took place on the basis of the preservation of students' art education as an internally integral system, in which each of the elements has its own typed solution (educational area "Art" in general secondary education, additional education, professional level education) and is the basis for the development of artistic and creative abilities students, formation of the foundations of professional culture and further expansion of the professional thesaurus. Building a didactic toolkit of students' art education based on: the correlation of goals and objectives, the specifics of the content (the essence of which is the acquisition of knowledge, skills and abilities about the foundations of the arts, updating towards the integration of types of arts, polyart education aimed at maximizing artistic and creative abilities the younger generation to different types of arts), a set of methods of artistic training and education aimed at developing not only a creatively oriented personality, but also socially and culturally adapted to the very complex requirements of the time, in connection with the actualization of the very concept of the "labor market".

The actualized practice-oriented orientation of the training of an art specialist is associated with:

- the development of creative activity of students of art educational institutions and enlightenal organizations through the development of new directions and forms of practical activity, which are associated with their socio-cultural adaptation to a wide audience through communication in the language of art, realizing that they are able to identify requests, develop artistic tastes, landmarks of society, namely: public exhibitions of works by students of art schools, art colleges; academic concerts of students of musical educational institutions (schools, colleges, academies); choreographic performances by students of choreographic schools; dramatizations by students of theater colleges; cinematographic experiences in the field of documentary, feature films by students of film workshops;

- the ability of students to compete - undoubtedly, it is important in the organization of art education to focus on teaching and educational tasks, taking into account the historical 
moment. In particular, due to the fact that today the concept of "labor market" has been actualized in art education by the time itself, it is necessary to strengthen the idea of educating a competitive personality - the formation in her of the ability for active selfeducation and self-realization in public life.

All this opened up opportunities for studying organizational and pedagogical experience and identifying relevant approaches to the development of a student's personality in the artistic field. The study of the pedagogical experience of organizing and building regional art education of students made it possible to formulate the most important principles continuity (thanks to which the link between the experience of the past and its application in modern conditions) and partnership at the interregional, interstate levels.

\section{References}

1. Sh.A. Amonashvili, Pedagogical Symphony, 667 (2002)

2. V.I. Zagvyazinsky, Practical methodology of pedagogical search, 72 (2005)

3. L.A. Stepashko, Historical and pedagogical theoretical research: scientific apparatus, 60 (2005)

4. L.A. Burovkina, Scientific and methodological conditions of art education of students in institutions of additional education: monograph, 320 (2011)

5. J. Dewey, Democracy and Education, 384 (2000)

6. P.F. Kapterev, History of Russian Pedagogy, 456 (2004)

7. Ya.A. Komensky, Labyrinth of Light and Heaven of the Heart, 320 (2000)

8. R. Berne, The development of the Self-concept and education, 422 (1986)

9. L.S. Vygotsky, Imagination and creativity in childhood: A psychological sketch, 93 (1991)

10. L.S. Vygotsky, Educational psychology, 536 (1996)

11. L.S. Vygotsky, Psychology of Art, 576 (1968)

12. T.I. Ivanyuk, Creativity and Personality, 320 (2006)

13. A.N. Leontiev, Activity. Consciousness. Personality, 175 (1996)

14. A. Maslow, Motivation and Personality, 352 (2003)

15. M.S. Kagan, Historical typology of artistic culture: Five lectures, 86 (1996)

16. V. Hoffman, Fundamentals of Contemporary Art: An Introduction to Its Symbolic Forms, 560 (2004)

17. L.N. Kogan, Sociology of culture, 120 (1992)

18. Yu.M. Lotman, Articles on the semiotics of culture and art, 312 (2002)

19. M. Heidegger, The Source of Artistic Creation, 526 (2005)

20. M.N. Epshtein, The future of the humanities: technogumanism, creatorics, eratology, electronic philology and other sciences of the XXI century, 239 (2019)

21. B. Taylor, Art Today: Contemporary Art 1970-2005, 256 (2006)

22. S.I. Kolbysheva, Aesthetic and art education as a sociocultural phenomenon, Art education and science, 2, 6-18 (2020)

23. E.V. Savelova, Prospects for International Cooperation in the Training of Specialists for the Sphere of Art and Culture, Higher Education in Russia, 7, 105-110 (2018) 
24. V.S. Senashenko, A.A. Makarova, Educational hybrids in higher education in Russia, Higher education in Russia, 8-9, 24-42 (2018)

25. E.O. Pakhomchikova, Designing a cycle of training sessions in a discipline from the standpoint of an activity-competence approach, Higher education in Russia, 4, 115 126 (2018)

26. Novonikolaevskaya province - Novosibirsk region. 1921-2000. Chronicle. Documents, 327 (2001) 